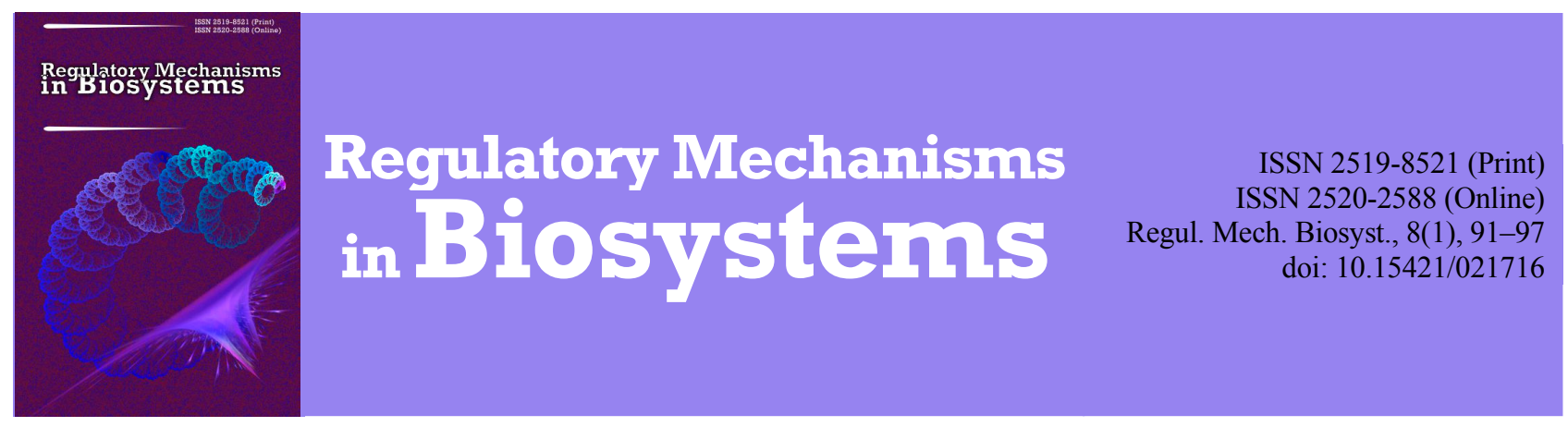

\title{
Central hemodynamic and splanchnic circulation in children with meningococcal septic shock
}

\author{
M. A. Georgiyants*, V. A. Korsunov*, O. M. Olkhovska** \\ *Kharkiv Medical Academy of Postgraduate Education, Kharkiv, Ukraine \\ **Kharkiv National Medical University, Kharkiv, Ukraine
}

Article info

Received 12.01.2017

Received in revised form 12.02.2017

Accepted 16.02.2017

Kultury Str., 11/83,

Kharkiv, 61058, Ukraine

Tel. +38-066-523-32-13

E-mail: eniram@bigmir.net

Ugrickogo Str., 16,

Kharkiv, 61000, Ukraine

Tel. +38-050-300-05-16

E-mail: korsunoff@ukr.net

N'uton Str., 123/37,

Kharkiv, 61162, Ukraine

$\mathrm{Tel}+38-095-193-12-44$

E-mail: onixol19@gmail.com

Georgiyants, M. A., Korsunov, V. A., \& Olkhovska, O. M. (2017). Central hemodynamic and splanchnic circulation in children with meningococcal septic shock. Regulatory Mechanisms in Biosystems, 8(1), 91-97. doi: $10.15421 / 021716$

Meningococcal infection is caused by the bacterium Neisseria meningitidis (also termed meningococcus). Invasive meningococcal disease remains a rare infectious disease not only with high mortality but also with important morbidity and remains as a leading cause of sepsis and septic shock. The pathogenic mechanisms of microcirculatory disorders in meningococcal septic shock have been subject to controversy. This article presents the results of a study of 11 paediatric patients' (4 boys and 7 girls) with meningococcal septic shock (Group I) who were hospitalized at the Regional Children's Infectious Hospital from 2009 to 2011. The average age of the patients was $37.4 \pm 8.4$ mo. Septic shock was diagnosed according to International Pediatric Sepsis Consensus Conference: definitions of criteria for sepsis and organ dysfunction in paediatrics. Heart rate, respiratory rate, systolic blood pressure, diastolic blood pressure, average blood pressure, $\mathrm{SpO}_{2}$ were monitored. The cardiac output, ejection fraction, fraction shortening, stroke volume were measured by ultrasound in M-mode by Teichholz method. Blood circulation in the a. mesenterica, a. hepatica, a. lienalis, a. renal sinister, v. porta, v. lienalis, v. renal sinister was determined by impulse Doppler's wave. Acid-base and electrolytes level in serum, nitric oxide (NO), endothelin I, creatinine, C-reactivity protein and lactate blood level were measured. The control group consisted of 21 healthy children ( 9 boys and 12 girls), aged $37.5 \pm 5.4$ mo. in average (Group II). We used t-criteria (Student's) and correlation with R-criteria (Spearmen) for statistical analysis. The data showed a statistically significant lower fraction of ejection, fraction of shortening, stroke volume in Group I. Moreover, our data showed a statistically high level of mesenterial and portal blood flow rate and high pulse index in $v$. renal sinister compared to healthy children. The blood level of NO was increased in Group I as well as in Group II. Direct correlations were determined between the level of NO and mesenteric, hepatic arterial and venous blood flow rate. Statistically significant inverse correlations between the level of NO and pulse resistive index in splanchnic vessels were discovered as well as inverse correlations between the NO level and the indicator of the severity of condition on PRISM scale $(\mathrm{r}=-0.952)$. At the same time, we have found no correlation between splanchnic circulation value and cardiac output. Based on the results of this study, we consider that NO has organ protective effects in children with meningococcal sepsis. Future research should aim to introduce new strategies of intensive care for patients with meningococcal septic shock with early use of inotrope and NO-donor therapy in fluid restriction combination.

Keywords: meningococcal sepsis; children; nitric oxide; portal circulation

\section{Introduction}

Meningococcal infection (MI) was first described by Vieusseux, Switzerland in 1805. Meningococcus (Neisseria meningitidis) was first identified in the cerebrospinal fluid of a patient with meningitis by Weichselbaum in 1887. According to WHO, MI has caused 171,000 deaths all over the world since the year 2000 (Hamborsky, 2015).

$N$. meningitidis leads to 500,000 cases of meningitis and septicemia in the world annually. Recent foreign data indicate a 5-15\% mortality rate of meningococcal diseases (Sadarangani et al., 2015). It remains highly distressing that MI can kill healthy people of any age within a few hours of the onset of the first symptoms.

In $1919 \mathrm{~W}$. W. Herrick pointed out, regarding meningococcal infection, "there is no other infection that kills so quickly" and this statement is still correct almost 100 years later. Meningococcal disease is the leading infectious factor in the death in children in the UK, despite the success of vaccination against meningococcus group
C. High mortality is not the only problem posed by meningococcal infection - more than a third of surviving patients have one or more clinically significant physical, cognitive or functional defects.

Overall, one in ten affected children can suffer such serious consequences as amputations and brain damage (Viner et al., 2012). Deaths and severe disability are usually associated with the fulminant course of meningococcal sepsis, the frequency of which is $10-20 \%$ and the mortality up to $80-100 \%$. The leading factor of death and serious complications of the skin and soft tissue with MI is septic shock (Nadel, 2016). In pathogenesis of septic shock the main role is played by disorders of the microcirculation and tissue perfusion or microcirculatory distress, which are based on the damage to the endothelium (De Backer et al., 2013; Ince et al., 2016). Long-term persistence of these disorders despite intensive therapy is one of the leading factors in the formation of multiple organ failure syndrome and unfavourable outputs in septic shock (De Backer et al., 2013).

It is known that two groups of mediators are involved in the regulation of vascular tone: vasoconstrictors (catecholamines, vaso- 
pressin, angiotensin II, endothelin, leukotrienes) and vasodilators (prostaglandins, serotonin, histamine, nitric oxide, atrial natriuretic peptide) (Boisrame-Helms et al., 2013). There is a hypothesis that explains the development of septic vasodilatation by an imbalance between vasodilators and vasoconstrictors in favour of vasodilators. However, vasodilatation affects not all vascular areas, but some vascular pools can be in a state of spasm, leading to a redistribution of blood flow through different parts of the microvasculature, as it is shown in patients with severe sepsis that the number of microvasculature vessels with normal blood circulation $(<20 \mu \mathrm{m})$ is significantly lower, compared to healthy volunteers (De Backer, 2014). Many studies have demonstrated that the slowdown of blood flow in micro vessels persists and causes a disturbance of oxygen consumption by tissues after solution resuscitation (Corrêa et al., 2016). In the experimental models of septic shock the rapid reduction in microcirculatory blood flow was detected, the formation of vessels with the ability to block blood circulation, increase in blood flow heterogeneity and reduction of the density of capillaries. It is emphasized that these disorders can occur in the absence of intensive hemodynamic changes and arterial hypotension (De Backer, 2014). Due to redistribution of blood flow, microcirculatory disorders lead to the development of multiple organ failure in septic shock syndrome and have to be corrected immediately by intensive care (Lupp et al., 2013). Thus, according to published data, vasodilation and vasoconstriction simultaneously appear in septic shock and are both responsible for damage to vital organs. However, in commonly adopted intensive care the major aim is to remove arterial hypotension (predominantly vasodilation) by using sympathomimetic drugs, which cause more severe vasoconstriction and closing of the vicious circle of septic shock. Nitric oxide (NO) is considered as the main vasodilator. The lifetime of $\mathrm{NO}$ is about $6 \mathrm{sec}$. after which it turns into nitrates $\left(\mathrm{NO}_{2}^{-}\right)$and nitrite $\left(\mathrm{NO}_{3}{ }^{-}\right)$. In septic shock $\mathrm{NO}$ formation is stimulated by LPS and pro-inflammatory cytokines from L-arginine due to the action of enzyme isoforms of NOsynthase. The formation of NO may also be as a result of restoration from $\mathrm{NO}_{2}^{-}$and $\mathrm{NO}_{3}{ }^{-}$by nitrate reductase systems (Zhao et al., 2015). The effect of NO on the microorganism is realized through activation of soluble guanylate cyclase in the endothelium. Consequently, synthesis of cyclic guanosine monophosphate increases, causing the relaxation of blood vessels and as a result - hypotension and increased capillary leakage (Zhao et al., 2015). Thus, an excess of NO in septic shock can reduce systemic and pulmonary vascular resistance, which in turn reduces the systemic and pulmonary blood pressure. Its abundance is also associated with the development of myocardial dysfunction and increased oxygen consumption. However, in septic shock vasodilatation and its effects are also likely to occur due to hypoxia and activation of potassium channels, lactic acidosis, and vasopressin deficiency.

Thus, in recent years, the alternative concept of the role of L-arginine and NO in septic shock has been formulated. According to this concept, as the result of the activation of the second path using inducible nitric oxide synthase, hyperproduction of NO is compensatory in nature due to the inhibition of NO production by constitutive NO-synthase III type that provides a sufficient level of NO required for maintaining adequate organ perfusion.

Thus, it has been suggested that, primarily affected by the prevalence of septic shock, vasoconstrictors improve organ perfusion due to the overproduction of NO (Duran-Bedolla et al., 2014). It is important to remember that if septic shock in adults is often accompanied by high cardiac output and low peripheral vascular resistance (predominant occurrence of vasodilation), then septic shock in children often has the opposite hemodynamic profile - low cardiac output and elevated or normal vascular resistance.

That's why the leading symptom of septic shock in adults is blood pressure reduction and in children - microcirculatory disorders (Dellinger et al., 2013). Therefore, it is logical to assume that a vasoconstrictor effect is dominant in children with septic shock. This assumption is more logical regarding meningococcal septic shock, thanks to expressive microcirculation disorders that cause necrosis of the skin and soft tissue more frequently than in any other diseases and the pathognomonic sign of meningococcemia-disseminated hemorrhagic rash with necrosis.

However, according to the concept of blood flow heterogeneity in septic shock, a question arises: Is vasoconstriction present in all vascular pools in children with meningococcal septic shock? The greatest interest lies in the state of blood circulation in the organs of the splanchnic zone (intestines, liver), which is the largest vascular area and normally requires up to $25 \%$ of cardiac output and characterizes multiple aspects of homeostasis (Prin et al., 2015). There is an evident interest in the condition of the renal circulation, because damage and dysfunction of the kidneys and organs of the splanchnic zone are integral components of the multiple organ failure syndrome. Meanwhile, the data about microcirculatory changes in these organs during septic shock remain highly controversial (Gomez et al., 2014; Bernal, 2016). The next question concerns the relationship between the cardiac output and the state of regional circulation. Unfortunately, in the sources available to us, we have found only a few papers devoted to the analysis of the central hemodynamic in children with meningococcal septic shock and were unable to locate even a single work on the state of the splanchnic organs and renal blood flow. Meanwhile, there are publications on the use of Doppler ultrasound for blood flow investigation of the afferent and efferent renal vessels and mentioning the high efficiency of this method for the prediction of acute kidney injury (Schnell et al., 2012). Thus, there is significant difference in opinion on the state of splanchnic and renal perfusion in cases of MI, dependence of blood perfusion on the balance of nitric oxide and endothelin. These aspects have not been researched in children with meningococcal septic shock, which is why the current investigation was carried out.

The purpose of the study was to assess the state of splanchnic (top mesenteric, common hepatic, splenic artery, splenic and portal venous) blood flow and renal blood flow in children with meningococcal septic shock and make a subsequent comparison of the obtained data with the serum concentration of nitric oxide and endothelin I. We also set the of goal of determining the relationship between the level of nitric oxide, endothelin and serum parameters of renal and splanchnic circulation, systemic inflammatory response and the severity of organ failure in children with meningococcal septic shock.

\section{Materials and methods}

The study involved 11 children ( 4 boys and 7 girls) aged from 7 months to 9 years $(34.9 \pm 8.5$ months on average), who were hospitalized in the ICU of Regional Children's Infectious Diseases Hospital (Kharkiv) in the years 2009-2011 and diagnosed with septic shock of meningococcal etiology (Group 1). Diagnosis of septic shock was established on the basis of criteria of the International Pediatric Sepsis Consensus Conference: definitions for sepsis and organ dysfunction in pediatrics (2005). The severity was evaluated on the basis of Glasgow Meningococcal Septicaemia Prognostic Score (GMSPS) - 9, $0.0 \pm 1.3$ points on average; scale of septic multiple organ failure SOFA $-10.1 \pm 1.2$ points and PRISM GPA scale $-20.4 \pm 3.2$ points on average.

Monitor observation of patients included the determination of the heart rate (HR), skin and rectal temperature gradient, electrocardiography, systolic (SBP), diastolic (DBP) and mean arterial pressure (MBP), central venous pressure (CVP), the frequency of respiratory movements $(\mathrm{RR})$, pulse oximetry $\left(\mathrm{SpO}_{2}\right)$ (monitors UM-300).

Simultaneously with intensive care measures (providing venous access, sedation, oxygen or endotracheal intubation, blood analysis and antibiotics therapy) all children underwent additional examination - M-mode echocardioscopy and pulsed-wave Doppler scan of blood flow in the liver (AH), splenic (AL ) and upper mesenteric (AM) arteries, portal (VP) and splenic (VL) veins (ultrasound scanner "Ultima PA"). HR, end-diastolic (LVEDD) and end-systolic (LVESD) size of the left ventricle was measured. According to the formula Teichholz et al. (1976), indices of left ventricular end-sys- 
tolic (LVESV) and end-diastolic volume (LVEDV), stroke volume (SV), stroke index (SI), ejection fraction (EF), contraction fraction (FS) were calculated. Cardiac output (HMV), cardiac index (CO) index and total peripheral vascular resistance (SVRI) were calculated by well-known formulae (Butterworth and Mackey, 2013). Also the diameter of blood vessels (D) of the portal vein, hepatic artery, splenic artery, upper mesenteric artery and splenic vein, the maximum $\left(\mathrm{V}_{\max }\right)$ and minimum $\left(\mathrm{V}_{\min }\right)$ blood flow speeds in these vessels were measured. According to the well-known formulae, the average blood flow velocity $\left(\mathrm{V}_{\text {mean }}\right)$, Pulse Code (RA), resistance index (IR), blood flow volume $\mathrm{Q}$, the ratio of blood flow to the body weight $\mathrm{Q} / \mathrm{m}$ and the indices of volumetric blood flow in the hepatic IBS AH and upper mesenteric artery IBS AM and their relationship to the $\mathrm{CO}$ (IBC/CO AH and IBC /CO AM) were calculated.

Besides, we determined the hepatic vascular index (HVI), splenoportal index (LPI), Doppler portal index (DPI), common hepatic blood volume flow (CHBV), hepatic portal ratio (HPR). With all patients the pulsed-wave Doppler scan blood flow in the left renal artery $\left(\mathrm{A}_{\text {ren }} \mathrm{S}\right)$ and $\left(\mathrm{V}_{\text {ren }} \mathrm{S}\right)$ vein was performed and the average flow velocity $\left(\mathrm{V}_{\text {mean }}\right)$, pulsation index $(\mathrm{PI})$ and resistance index (IR) were calculated based on the results of maximum $\left(\mathrm{V}_{\max }\right)$ and minimum $\left(\mathrm{V}_{\text {min }}\right)$ flow rate. Parameters of acid-base status and gases of arterial and central venous blood were measured by analyzer AVL - 995 and Gastat - mini. The level of hemoglobin $(\mathrm{Hb})$ was determined by the colorimetric method. The calculation of oxygen supply $\mathrm{DO}_{2}$, oxygen consumption $\mathrm{VO}_{2}$ and an index of tissue oxygen extraction was carried out by known formulae. The level of glucose was determined by analyzer "Exsan - G". C-reactive protein and endothelin I was measured by immuno-enzyme analysis (ELISA-test, USA), creatinine - by the method of Jaffe, content of blood lactate - enzymatic method with "Olvex diagnosticum" (Russia) by biochemical analyzer Stat Fax 1904+. The content of NO was assessed by serum final metabolites (nitrites/nitrates) by colorimetric method using the Griess reagent in the Central Research Laboratory of Kharkov National Medical University.

The control group (Group II) was formed of 21 practically healthy children ( 9 boys and 12 girls) (average age $37.5 \pm 5.4 \mathrm{mo}$ ). The parameters of central hemodynamics indices, Doppler parameters of blood circulation in the vessels of splanchnic zone, kidneys and NO metabolites content and serum endothelin I were established in the control group. Statistical processing of the obtained data was carried out by means of Statistica 7.0 (StatSoft Inc., USA) applications.

The test of normality was carried out according to the Kolmogorov-Smirnov criterion. Output data were subordinated to a normal distribution, so the significance of differences between groups was determined by the t-test (Student's test) and correlations between the parameters - using the rank correlation coefficient $\mathrm{R}$ (Spearman).

\section{Results and discussion}

Patients of the study Group I and the control Group II were not significantly different in age and anthropometric parameters and therefore can be comparable for further analysis of hemodynamic parameters and indicators of splanchnological and renal blood flow (Table 1).

Table 1

General characteristics of Groups (Mean \pm SE)

\begin{tabular}{lccc}
\hline \multicolumn{1}{c}{ Indices } & Group I, $\mathrm{n}=11$ & Group II, $\mathrm{n}=21$ & $\mathrm{P}$ \\
\hline Age, mo & $34.9 \pm 8.5$ & $37.5 \pm 5.4$ & 0.761 \\
Height, $\mathrm{cm}$ & $106.1 \pm 4.6$ & $99.0 \pm 5.9$ & 0.243 \\
Body weight, $\mathrm{kg}_{\text {Body area, } \mathrm{m}^{2}}$ & $14.9 \pm 1.9$ & $14.3 \pm 2.3$ & 0.782 \\
\hline
\end{tabular}

Children from Group I showed signs of systemic inflammatory response in the form of fever, tachypnea, tachycardia, leukocytosis (or leukopenia), increased levels of C-reactive protein (normally less than $6 \mathrm{mg} / \mathrm{l}$ ), which gave rise to the diagnosis of meningococcal sepsis based on combination of abundant hemorrhagic rash and results of bacteriological examination (emphasis of meningococcal groups A, B or C in the blood or nasal-throat) (Table 2). Indicators of central hemodynamics in Group I were characterized by significantly increased heart rate and reduced rates of systolic, diastolic and common arterial pressure. These changes are typical of decompensated septic shock. Indicators of the diastolic-end and systolic- end dimensions and volumes of the left ventricle in Group I and Group II did not differ significantly, but due to the decrease of EDLVD and increase of ESLVD, we investigated a decrease in the left ventricular systolic function, which includes ejection and contraction fractions. Stroke volume and left ventricular stroke indices were significantly lower in Group I compared to Group II. However, integrated cardiac output indices - the volume of blood and heart index were similar in both groups. Despite reduced SV and SI, significant differences between MHV and CO in both groups were absent due to tachycardia in Group I. The total peripheral vascular resistance was not significantly different between the groups (Table 3).

\section{Table 2}

Indicators of systemic inflammatory response and clinical signs of shock in Group I patients, $\mathrm{n}=11$ (Mean $\pm \mathrm{SE})$

\begin{tabular}{lc}
\hline Indices & Group I \\
\hline $\mathrm{HR}, 1 / \mathrm{min}$ & $163.3 \pm 6.3$ \\
$\mathrm{RR}, 1 / \mathrm{min}$ & $65.2 \pm 4.1$ \\
The number of leukocytes, $10^{9} / 1$ & $14.9 \pm 2.7$ \\
Body temperature, ${ }^{\circ} \mathrm{C}$ & $39.2 \pm 0.3$ \\
C-reactive protein, $\mathrm{mg} / \mathrm{l}$ & $98.2 \pm 13.5$ \\
Time of filling the capillaries, s & $5.6 \pm 0.4$ \\
Bad peripheral pulse, $\%$ & 100.0 \\
\hline
\end{tabular}

Table 3

Indicators of central hemodynamics in patients (Mean $\pm \mathrm{SE}$ )

\begin{tabular}{lccc}
\hline \multicolumn{1}{c}{ Indices } & Group $\mathrm{I}, \mathrm{n}=11$ & Group II, $\mathrm{n}=21$ & $\mathrm{P}$ \\
\hline SBP, $\mathrm{mm} \mathrm{Hg.}$ & $79.8 \pm 2.0$ & $101.5 \pm 1.0$ & $1.0 \cdot 10^{-7}$ \\
DBP, $\mathrm{mm} \mathrm{Hg}$. & $43.4 \pm 3.0$ & $57.3 \pm 1.4$ & 0.001 \\
MBP, $\mathrm{mm} \mathrm{Hg.}$ & $55.5 \pm 2.6$ & $72.1 \pm 1.1$ & $2.0 \cdot 10^{-6}$ \\
EDLVD, mm & $28.9 \pm 0.02$ & $30.4 \pm 0.07$ & 0.540 \\
ESLVD, mm & $21.9 \pm 0.02$ & $18.8 \pm 0.07$ & 0.137 \\
EDLVV, ml & $35.5 \pm 7.40$ & $37.2 \pm 2.79$ & 0.830 \\
ESLVV, ml & $18.5 \pm 4.42$ & $11.3 \pm 1.03$ & 0.118 \\
$\mathrm{SV}, \mathrm{ml} / \mathrm{m}^{2}$ & $17.0 \pm 3.11$ & $25.8 \pm 1.89$ & 0.025 \\
$\mathrm{SI}, \mathrm{ml} / \mathrm{min}^{2} / \mathrm{m}^{2}$ & $24.7 \pm 2.97$ & $43.7 \pm 2.25$ & $5.6 \cdot 10^{-5}$ \\
$\mathrm{HMV}, 1 / \mathrm{min}_{\mathrm{CO}, 1 / \mathrm{min} / \mathrm{m}^{2}}$ & $2.7 \pm 0.44$ & $2.6 \pm 0.16$ & 0.775 \\
EF, $\%$ & $4.0 \pm 0.42$ & $4.4 \pm 0.22$ & 0.394 \\
FS, $\%$ & $51.0 \pm 3.0$ & $70.0 \pm 1.0$ & $1.0 \cdot 10^{-6}$ \\
$\mathrm{SVRI}, \mathrm{din} \times \mathrm{S} \times \mathrm{cm}^{-5} \times \mathrm{m}^{2}$ & $1150.2 \pm 132.9$ & $1371.8 \pm 68.4$ & 0.152 \\
\hline
\end{tabular}

Thus, the indicators for analysis of central hemodynamics in children with meningococcal septic shock give reasons to recognize a significant deterioration of left ventricular systolic function as the leading factor of hemodynamic disorders, which in time offsets a significant increase in the heart rate. Despite the rather high cardiac output at normal ISVR of patients in Group II there was significant hypotension. We can assume that the second important factor which causes hemodynamic instability in the examined patients was the relative angioparesis, which made it impossible to maintain normal blood pressure. Analysis of acid-base status in patients of Group I indicates that they suffered from decompensated metabolic acidosis with increased anion interval. The possible reason for this was hyperlactatemia. Moderate anemia, hypercalcemia and increased creatinine were also observed. Usually, hypercalcemia is an atypical phenomenon for septic shock, but in our opinion, it was caused by the introduction of calcium to patients in prehospital emergency care. The increased level of creatinine indicates acute kidney damage in patients of Group I. Transport and consumption of oxygen were characterized by the moderate decrease in oxygen delivery with saved oxygen consumption, which is typical for the subcompensated state (Table 4).

Analysis of the blood flow in arterial vessels in the splanchnic zone shows the differences between Group I and the control Group II. Blood flow in the hepatic artery in Group I was characterized by 
significant growth of diastolic velocity Vmin accompanied by a significant decrease of pulsating index and resistance index compared to Group II. These changes follow the development of angioparesis in the hepatic artery. However, the volume flow rates of Groups I and II were not significantly different. So angioparesis may be viewed as compensatory within autoregulation of circulation in the internal organs to promote the required volume of blood circulation in the systemic arterial hypotension (Table 5).

In a. mesenterica of Group I we observed an almost double growth of $\mathrm{V}_{\max }$ was observed up to $181.6 \pm 26.4 \mathrm{sm} / \mathrm{s}$, statistically unreliable tendency to increase the pulse index and resistance index with significant increase in the blood flow volume relating to body weight $\mathrm{Q} / \mathrm{m}$ to $75.3 \pm$ $11.0 \mathrm{ml} / \mathrm{min} / \mathrm{m}^{2}$ compared to $46.6 \pm 4.5 \mathrm{ml} / \mathrm{min} / \mathrm{m}^{2}$ in Group II. Such changes of mesenteric blood flow should be considered as arterial congestion or excessive arterial blood supply, which leads to partial compensation in the form of arterial spasm development as autoregulation mechanisms of organ blood flow. We can exclude postprandial increase in blood flow in a. mesenterica because of the critical condition of children on empty stomachs who were admitted to the intensive care.

\section{Table 4}

Indicators of acid-base, fluid and electrolyte balance, oxygen transport and oxygen consumption in Group I patients, $\mathrm{n}=11,($ Mean $\pm \mathrm{SE})$

\begin{tabular}{|c|c|}
\hline Indices & Group I, $\mathrm{n}=11$ \\
\hline $\mathrm{Hb}, \mathrm{g} / \mathrm{l}$ & $105.9 \pm 4.7$ \\
\hline $\mathrm{PaO}_{2}, \mathrm{~mm} \mathrm{Hg}$ & $124.4 \pm 21.1$ \\
\hline $\mathrm{SaO}_{2}, \%$ & $95.3 \pm 1.6$ \\
\hline $\mathrm{PCVO}_{2}, \mathrm{~mm} \mathrm{Hg}$ & $53.2 \pm 5.4$ \\
\hline $\mathrm{SvO}_{2}, \%$ & $76.2 \pm 4.1$ \\
\hline $\mathrm{PaCO}_{2}, \mathrm{~mm} \mathrm{Hg}$ & $30.1 \pm 1.6$ \\
\hline $\mathrm{pH}$ & $7.27 \pm 0.06$ \\
\hline $\mathrm{AB}, \mathrm{mmol} / \mathrm{l}$ & $15.5 \pm 1.9$ \\
\hline $\mathrm{BB}, \mathrm{mmol} / \mathrm{l}$ & $34.9 \pm 3.3$ \\
\hline $\mathrm{BE}, \mathrm{mmol} / \mathrm{l}$ & $-11.6 \pm 3.5$ \\
\hline A gap, mmol/l & $34.9 \pm 3.3$ \\
\hline $\mathrm{Na}^{+}, \mathrm{mmol} / \mathrm{l}$ & $146.4 \pm 3.6$ \\
\hline $\mathrm{K}^{+}, \mathrm{mmol} / \mathrm{l}$ & $4.69 \pm 0.76$ \\
\hline $\mathrm{iCa}^{++}, \mathrm{mmol} / \mathrm{l}$ & $1.43 \pm 0.34$ \\
\hline $\mathrm{Cl}^{-}, \mathrm{mmol} / \mathrm{l}$ & $105.8 \pm 2.4$ \\
\hline Venous blood Lactate, $\mathrm{mmol} / 1$ & $6.51 \pm 2.17$ \\
\hline Creatinine, $\mathrm{mkmol} / \mathrm{l}$ & $187.3 \pm 45.5$ \\
\hline $\mathrm{DO}_{2}, 1 / \mathrm{min} / \mathrm{m}^{2}$ & $517.9 \pm 44.0$ \\
\hline $\mathrm{VO}_{2}, 1 / \mathrm{min} / \mathrm{m}^{2}$ & $124.7 \pm 32.5$ \\
\hline ITEO $_{2}, \%$ & $21 \pm 4$ \\
\hline
\end{tabular}

Blood flow in a. lienalis in patients in Group I was not significantly different in comparison with indicators of Group II (Table 5). Blood flow in $v$. portae in Group I was characterized by statistically significant increase of maximum, minimum and average linear blood flow compared with Group II. Increase of volumetric flow only had a statistically unreliable tendency. Indicators in the splenic vein flow had no significant differences between the study groups (Table 6).

Thus, in our opinion, the changes in blood flow in the portal vein should be also considered as a compensatory reaction to increase the blood supply of the liver. Taking into account the background of septic shock, we can consider a growing need for oxygen because of indirect systemic inflammatory response among the reasons for increased blood flow of the liver. In compensatory reaction to the arterial hypotension, we can observe the activation of Kuepfer macrophages and synthesis of acute phase proteins.

In analysis of the indices of blood flow in the hepatic artery, we haven't found any significant differences between Groups I and II. However, the blood flow volume index and its relation to body weight in Group II in the upper mesenteric artery were significantly higher than in Group I. The presence of significant differences between the indicators HVI, DPI and HPR reflect the relatively higher proportion of blood supply to the liver with the portal system and relatively smaller one with the hepatic artery system together with a statistically unreliable tendency to increase the overall volume of hepatic blood flow (Table 7).
Table 5

State of blood flow in blood vessels (Mean \pm SE)

\begin{tabular}{|c|c|c|c|}
\hline Indices & Group I, $\mathrm{n}=11$ & Group II, $\mathrm{n}=21$ & $\mathrm{P}$ \\
\hline \multicolumn{4}{|c|}{$\mathrm{AH}$} \\
\hline $\mathrm{V}_{\max }, \mathrm{cm} / \mathrm{s}$ & $90.8 \pm 18.1$ & $63.7 \pm 3.1$ & 0.008 \\
\hline $\mathrm{V}_{\min }, \mathrm{cm} / \mathrm{s}$ & $27.1 \pm 5.4$ & $14.3 \pm 1.1$ & 0.678 \\
\hline $\mathrm{V}_{\text {mean }}, \mathrm{cm} / \mathrm{s}$ & $48.1 \pm 9.0$ & $28.0 \pm 3.0$ & 0.073 \\
\hline PI & $1.30 \pm 0.11$ & $1.61 \pm 0.06$ & 0.135 \\
\hline IR & $0.69 \pm 0.03$ & $0.78 \pm 0.01$ & 0.182 \\
\hline $\mathrm{D}, \mathrm{cm}$ & $0.28 \pm 0.03$ & $0.32 \pm 0.03$ & 0.786 \\
\hline $\mathrm{Q}, \mathrm{ml} / \mathrm{min}$ & $249.8 \pm 47.4$ & $291.8 \pm 44.1$ & 0.212 \\
\hline $\mathrm{Q} / \mathrm{m}, \mathrm{ml} / \mathrm{min} / \mathrm{m}^{2}$ & $20.5 \pm 5.2$ & $20.4 \pm 1.4$ & 0.030 \\
\hline \multicolumn{4}{|c|}{$\mathrm{AM}$} \\
\hline $\mathrm{V}_{\max }, \mathrm{cm} / \mathrm{s}$ & $181.6 \pm 26.4$ & $100.4 \pm 4.6$ & 0.064 \\
\hline $\mathrm{V}_{\min }, \mathrm{cm} / \mathrm{s}$ & $21.4 \pm 2.1$ & $25.8 \pm 9.0$ & 0.064 \\
\hline $\mathrm{V}_{\text {mean }}, \mathrm{cm} / \mathrm{s}$ & $74.8 \pm 9.7$ & $50.6 \pm 7.2$ & 0.057 \\
\hline PI & $2.08 \pm 0.09$ & $1.72 \pm 0.19$ & 0.817 \\
\hline IR & $0.87 \pm 0.02$ & $0.76 \pm 0.07$ & 0.807 \\
\hline $\mathrm{D}, \mathrm{cm}$ & $0.41 \pm 0.02$ & $0.41 \pm 0.01$ & 0.241 \\
\hline $\mathrm{Q}, \mathrm{ml} / \mathrm{min}$ & $1075.4 \pm 237.9$ & $698.0 \pm 149.1$ & 0.315 \\
\hline $\mathrm{Q} / \mathrm{m}, \mathrm{ml} / \mathrm{min} / \mathrm{m}^{2}$ & $75.3 \pm 11.1$ & $46.6 \pm 4.5$ & 0.378 \\
\hline \multicolumn{4}{|c|}{$\mathrm{AL}$} \\
\hline$\overline{V_{\max }, \mathrm{cm} / \mathrm{s}}$ & $97.2 \pm 15.1$ & $67.3 \pm 3.0$ & 0.064 \\
\hline $\mathrm{V}_{\min }, \mathrm{cm} / \mathrm{s}$ & $26.2 \pm 4.0$ & $17.9 \pm 1.3$ & 0.064 \\
\hline $\mathrm{V}_{\text {mean }}, \mathrm{cm} / \mathrm{s}$ & $50.1 \pm 7.5$ & $31.2 \pm 3.3$ & 0.057 \\
\hline PI & $1.43 \pm 0.06$ & $1.45 \pm 0.06$ & 0.817 \\
\hline IR & $0.73 \pm 0.02$ & $0.73 \pm 0.01$ & 0.807 \\
\hline $\mathrm{D}, \mathrm{cm}$ & $0.31 \pm 0.02$ & $0.34 \pm 0.01$ & 0.241 \\
\hline $\mathrm{Q}, \mathrm{ml} / \mathrm{min}$ & $467.0 \pm 124.1$ & $330.6 \pm 38.7$ & 0.315 \\
\hline $\mathrm{Q} / \mathrm{m}, \mathrm{ml} / \mathrm{min} / \mathrm{m}^{2}$ & $34.1 \pm 10.7$ & $24.2 \pm 2.3$ & 0.378 \\
\hline
\end{tabular}

Table 6

State of blood flow in the portal and splenic veins (Mean \pm SE)

\begin{tabular}{lccc}
\hline \multicolumn{1}{c}{ Indices } & Group I, $\mathrm{n}=11$ & Group II, $\mathrm{n}=21$ & $\mathrm{P}$ \\
\hline \multicolumn{3}{c}{ VP } \\
\hline $\mathrm{V}_{\max }, \mathrm{cm} / \mathrm{s}$ & $29.1 \pm 4.2$ & $16.6 \pm 0.7$ & 0.010 \\
$\mathrm{~V}_{\min }, \mathrm{cm} / \mathrm{s}$ & $14.5 \pm 1.3$ & $11.2 \pm 0.5$ & 0.007 \\
$\mathrm{~V}_{\text {mean }}, \mathrm{cm} / \mathrm{s}$ & $17.0 \pm 1.5$ & $13.0 \pm 0.6$ & 0.007 \\
$\mathrm{PI}$ & $0.45 \pm 0.03$ & $0.42 \pm 0.02$ & 0.122 \\
$\mathrm{IR}$ & $0.34 \pm 0.02$ & $0.33 \pm 0.01$ & 0.129 \\
$\mathrm{D}, \mathrm{cm}$ & $0.56 \pm 0.05$ & $0.58 \pm 0.02$ & 0.356 \\
$\mathrm{Q}, \mathrm{ml} / \mathrm{min}$ & $489.9 \pm 95.0$ & $328.0 \pm 32.5$ & 0.131 \\
$\mathrm{Q} / \mathrm{m}, \mathrm{ml} / \mathrm{min} / \mathrm{m}^{2}$ & $38.0 \pm 9.5$ & $24.5 \pm 1.3$ & 0.178 \\
\hline \multicolumn{4}{c}{$\mathrm{VL}$} \\
\hline $\mathrm{V}_{\max }, \mathrm{cm} / \mathrm{s}$ & $20.6 \pm 3.2$ & \\
$\mathrm{~V}_{\min }, \mathrm{cm} / \mathrm{s}$ & $16.2 \pm 3.0$ & $22.1 \pm 1.2$ \\
$\mathrm{~V}_{\operatorname{mean}}, \mathrm{cm} / \mathrm{s}$ & $17.7 \pm 3.1$ & $18.2 \pm 1.1$ & 0.667 \\
$\mathrm{PI}$ & $0.31 \pm 0.07$ & $0.34 \pm 0.04$ & 0.998 \\
$\mathrm{IR}$ & $0.24 \pm 0.04$ & $0.27 \pm 0.03$ & 0.672 \\
$\mathrm{D}, \mathrm{cm}$ & $0.56 \pm 0.05$ & $0.40 \pm 0.02$ & 0.534 \\
$\mathrm{Q}, \mathrm{ml} / \mathrm{min}$ & $246.5 \pm 57.8$ & $237.1 \pm 27.9$ & 0.947 \\
$\mathrm{Q} / \mathrm{m}, \mathrm{ml} / \mathrm{min} / \mathrm{m}^{2}$ & $18.0 \pm 4.6$ & $17.5 \pm 1.6$ \\
\hline
\end{tabular}

Table 7

Indices of portal blood flow in the hepatic and upper mesenteric arteries (Mean $\pm \mathrm{SE}$ )

\begin{tabular}{lccc}
\hline \multicolumn{1}{c}{ Indices } & Group I, $\mathrm{n}=11$ & Group II, $\mathrm{n}=21$ & $\mathrm{P}$ \\
\hline IBC AH & $1795.9 \pm 373.8$ & $1202.8 \pm 168.5$ & 0.175 \\
IBC AM & $7324.3 \pm 1423.6$ & $2860.4 \pm 568.7$ & 0.011 \\
IBC/CI AH & $47.8 \pm 9.0$ & $28.3 \pm 5.0$ & 0.083 \\
IBC/CI AM & $194.7 \pm 41.8$ & $68.4 \pm 16.6$ & 0.013 \\
HVI, cm $/ \mathrm{s}$ & $16.7 \pm 2.2$ & $6.7 \pm 0.3$ & 0.001 \\
LPI, \% & $67.6 \pm 21.2$ & $78.0 \pm 7.4$ & 0.667 \\
DPI & $0.35 \pm 0.03$ & $0.50 \pm 0.05$ & 0.012 \\
CHBV, $\mathrm{ml} / \mathrm{min}$ & $739.7 \pm 136.4$ & $563.4 \pm 41.2$ & 0.220 \\
HPR & $0.56 \pm 0.08$ & $0.74 \pm 0.09$ & 0.025 \\
\hline
\end{tabular}

No significant differences in blood flow parameters between Groups I and II were found. Indicators of blood flow in the left renal vein showed no differences between Groups I and II, except that the pulse index (PI) in patients of Group I with meningococcal septic shock was significantly higher than in Group II. Thus, in patients with septic shock of meningococcal etiology a substantial 
and clinically significant renal venous vasoconstriction was observed (Table 8).

\section{Table 8}

State of blood flow in the left renal artery and vein (Mean \pm SE)

\begin{tabular}{lccc}
\hline \multicolumn{1}{c}{ Indices } & Group I, $\mathrm{n}=11$ & Group II, $\mathrm{n}=21$ & $\mathrm{P}$ \\
\hline \multicolumn{4}{c}{$\mathrm{A}_{\text {ren }} \mathrm{S}$} \\
\hline $\mathrm{V}_{\text {max }}, \mathrm{cm} / \mathrm{s}$ & $55.1 \pm 8.6$ & $68.0 \pm 3.7$ & 0.182 \\
$\mathrm{~V}_{\text {min, }}, \mathrm{cm} / \mathrm{s}$ & $14.9 \pm 2.8$ & $16.8 \pm 1.3$ & 0.539 \\
$\mathrm{~V}_{\text {mann }}, \mathrm{cm} / \mathrm{s}$ & $28.3 \pm 4.5$ & $33.8 \pm 1.7$ & 0.257 \\
$\mathrm{PI}$ & $1.46 \pm 0.16$ & $1.52 \pm 0.08$ & 0.762 \\
$\mathrm{IR}$ & $0.72 \pm 0.04$ & $0.75 \pm 0.02$ & 0.546 \\
\hline \multicolumn{4}{c}{$\mathrm{V}_{\text {ren }} \mathrm{S}$} \\
$\mathrm{V}_{\text {max }}, \mathrm{cm} / \mathrm{s}$ & $19.8 \pm 3.0$ & $17.2 \pm 0.9$ & 0.402 \\
$\mathrm{~V}_{\text {min }}, \mathrm{cm} / \mathrm{s}$ & $9.9 \pm 1.5$ & $11.6 \pm 0.5$ & 0.276 \\
$\mathrm{~V}_{\text {mann }}, \mathrm{cm} / \mathrm{s}$ & $13.2 \pm 1.8$ & $13.5 \pm 0.6$ & 0.880 \\
$\mathrm{PI}$ & $0.73 \pm 0.15$ & $0.41 \pm 0.03$ & 0.042 \\
$\mathrm{IR}$ & $0.45 \pm 0.07$ & $0.32 \pm 0.02$ & 0.056 \\
\hline
\end{tabular}

Basically, the results of our data on the specificity of venous vasoconstriction, which is mostly characterized by a decrease in diastolic flow velocity and the development of acute kidney damage are similar to those of other researchers (Fig. 1). Correlation analysis of indicators of renal venous flow revealed the presence of significant connection between $\mathrm{V}_{\min }$ in the renal vein and creatinine $(\mathrm{R}=-0.840$, $\mathrm{P}<0.05)$. The Pulse Index of renal veins in Group II never exceeded the mark of $0.53(\mathrm{Max}=0.53, \mathrm{Min}=0.22)($ Fig. 2). To assess the impact of vasoactive mediators on blood flow distribution to different vascular zones, we explored the content of total serum metabolites of nitric oxide $\left(\mathrm{NO}_{2}^{-}+\mathrm{NO}_{3}^{-}\right)$and concentration of endothelin I in blood. It was found that children in Group I had a significant increase of nitric oxide metabolites in comparison to those in Group II. Despite a tendency to slight increase of endothelin I concentration in Group I, there were no significant difference between the groups (Table 9).

Table 9

Content of NO final metabolites and serum lactate (Mean \pm SE)

\begin{tabular}{lccc}
\hline \multicolumn{1}{c}{ Indices } & Group I, $\mathrm{n}=11$ & Group II, $\mathrm{n}=21$ & $\mathrm{P}$ \\
\hline The total NO metabolites, $\mathrm{mkmol} / 1$ & $51.3 \pm 8.3$ & $29.3 \pm 2.5$ & 0.014 \\
Endothelin I, pmol/1 & $0.70 \pm 0.35$ & $0.24 \pm 0.01$ & 0.264 \\
\hline
\end{tabular}

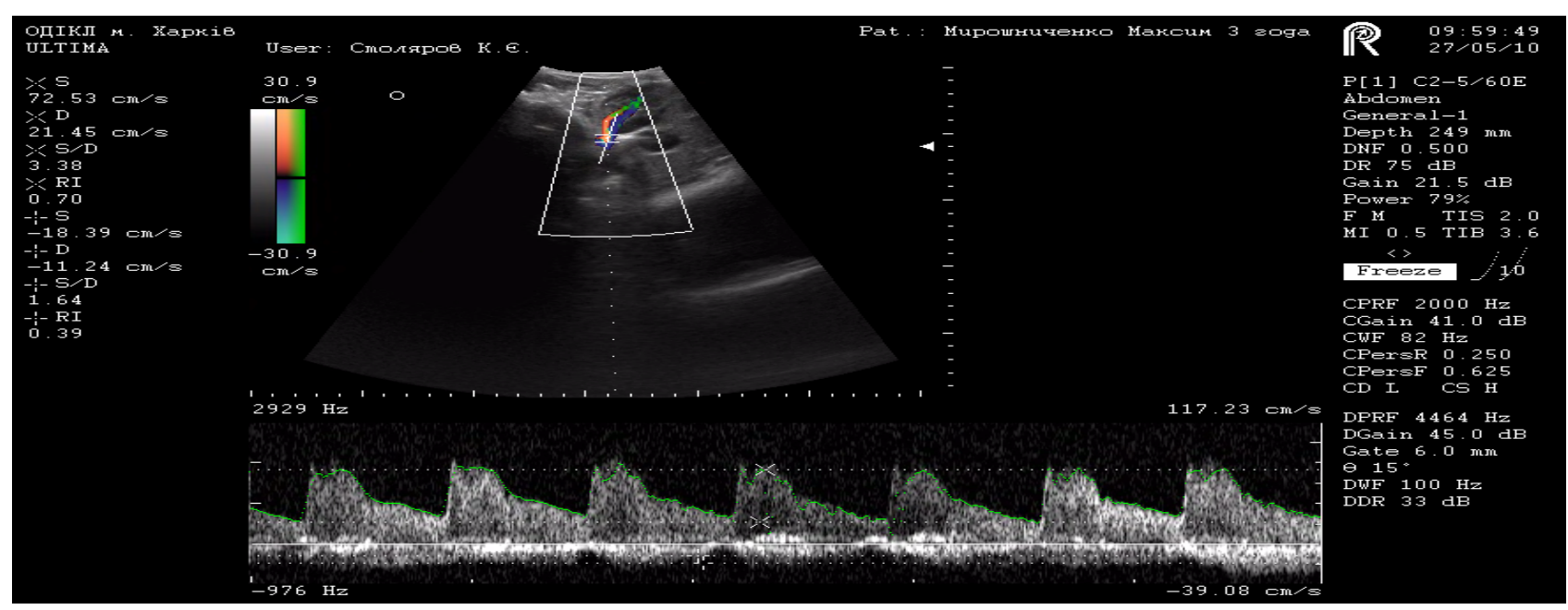

Fig. 1. Renal blood flow in baby with septic shock

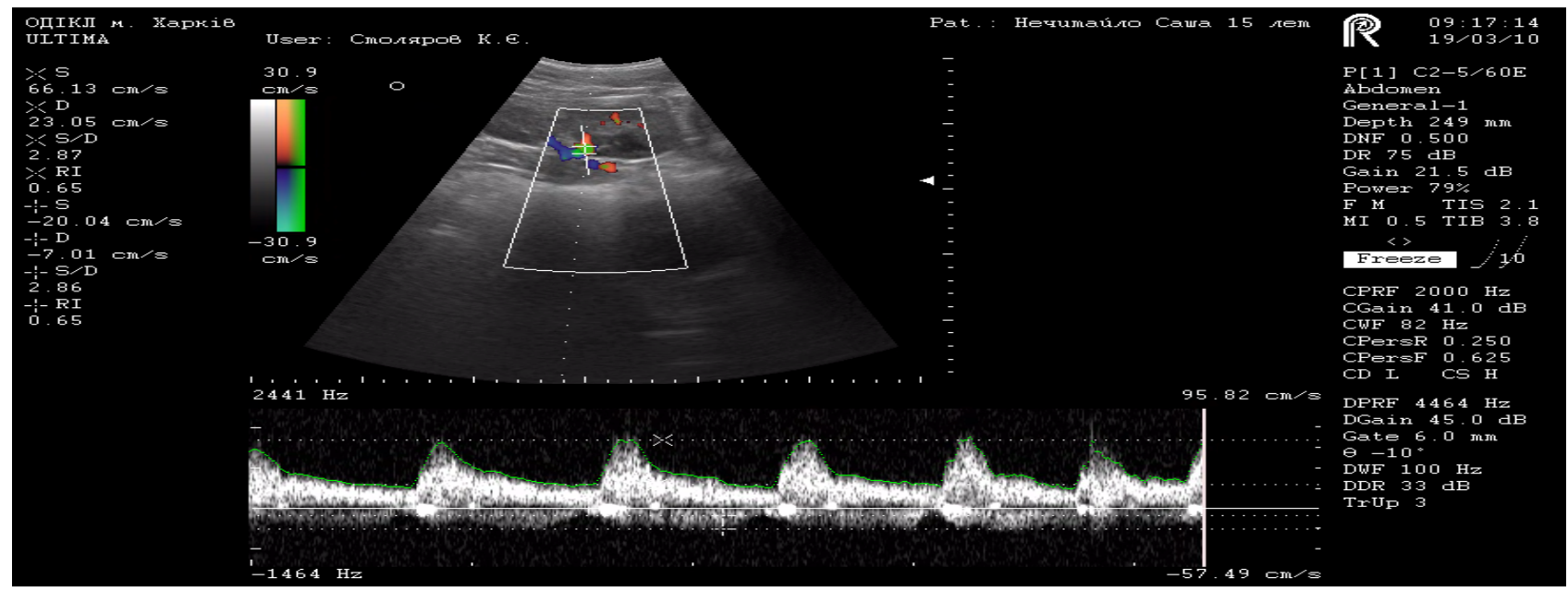

Fig. 2. Renal blood flow in healthy child

In order to determine the presence of relations between the states of regional blood flow, we conducted a correlation analysis of systemic inflammatory response, severity and studied vasoactive mediators. This analysis revealed strong positive relations between cumulative NO metabolites, speed of blood flow through the vessels in the splanchnic zone, diameter of vessels, pulse index and index of resistance. The direction of these connections testified the dependence of the vascular zone on NO, which has the ability of NO to cause vasodilation in liver and upper mesenteric artery, splenic and portal veins. The direct relation of NO with the number of polymorphic nuclear neutrophils and reverse assessment scale of PRISM may indicate the increased production of $\mathrm{NO}$ which has a positive impact on patients recovering from meningococcal septic shock. Unlike NO, the endothelin correlation with indicators of vascular tone is evidence of its vasoconstrictive effect. Besides, endothelin had a direct relation with C-reactive protein. Based on our obtained data, we set ourselves the question about the role of cardiac output in influence on the performance of regional circulation. 
In order to answer this question, we conducted a correlation analysis between the cardiac output measure and those indicators that demonstrated a close correlation with vasoactive mediators. In none of the cases did the SO have significant correlations with indicators of regional blood flow and systemic inflammatory response or severity of the examined patients' status (Table 10). We haven't found any significant correlation between indicators of central hemodynamics and $\mathrm{NO}$, which may probably refute the traditional view of the ability of NO to cause myocardial depression in sepsis (Table 11).

\section{Table 10}

Correlation between cardiac output, vasoactive mediators, indicators of organ blood flow, systemic inflammatory response and the severity of Group I

\begin{tabular}{|c|c|c|}
\hline Indices & $\mathrm{R}$ & $\mathrm{P}$ \\
\hline $\mathrm{V}_{\min } \mathrm{AH}-\mathrm{CO}$ & -0.200 & $>0.05$ \\
\hline $\mathrm{V}_{\min } \mathrm{AH}-\mathrm{NO}$ & -0.710 & $<0.05$ \\
\hline IR VP-CO & -0.083 & $>0.05$ \\
\hline IR VP - NO & -0738 & $<0.05$ \\
\hline $\mathrm{PI} \mathrm{VP}-\mathrm{CO}$ & -0.083 & $>0.05$ \\
\hline $\mathrm{PI} V \mathrm{P}-\mathrm{NO}$ & -0.738 & $<0.05$ \\
\hline $\mathrm{D} \mathrm{AM}-\mathrm{CO}$ & 0.368 & $>0.05$ \\
\hline $\mathrm{D} A M-\mathrm{NO}$ & 0.826 & $<0.05$ \\
\hline $\mathrm{V}_{\max } \mathrm{VL}-\mathrm{CO}$ & 0.000 & $>0.05$ \\
\hline $\mathrm{V}_{\max } \mathrm{VL}-\mathrm{NO}$ & 0.785 & $<0.05$ \\
\hline $\mathrm{V}_{\min } \mathrm{VL}-\mathrm{CO}$ & 0.000 & $>0.05$ \\
\hline $\mathrm{V}_{\min } \mathrm{VL}-\mathrm{NO}$ & 0.780 & $<0.05$ \\
\hline $\mathrm{V}_{\text {mean }} \mathrm{VL}-\mathrm{CO}$ & 0.000 & $>0.05$ \\
\hline $\mathrm{V}_{\text {mean }} \mathrm{VL}-\mathrm{NO}$ & 0.780 & $<0.05$ \\
\hline PRISM - CO & 0.118 & $>0.05$ \\
\hline PRISM - NO & -0.952 & $<0.05$ \\
\hline Polymorphonuclear neutrophils - CO & 0.358 & $>0.05$ \\
\hline Polymorphonuclear neutrophils - NO & 0.845 & $<0.05$ \\
\hline IR VL-CO & -0.283 & $>0.05$ \\
\hline IR VL - endothelin I & 0.730 & $<0.05$ \\
\hline PI VL-CO & -0.283 & $>0.05$ \\
\hline PI VL - endothelin I & 0.730 & $<0.05$ \\
\hline $\mathrm{DAL}-\mathrm{CO}$ & 0.193 & $>0.05$ \\
\hline D AL - endothelin I & -0.672 & $<0.05$ \\
\hline $\mathrm{DVP}-\mathrm{CO}$ & -0.122 & $>0.05$ \\
\hline D VP-endothelin I & -0.666 & $<0.05$ \\
\hline IR VL-CO & -0.283 & $>0.05$ \\
\hline IR VL-endothelin I & 0.732 & $<0.05$ \\
\hline PI VL-CO & -0.283 & $>0.05$ \\
\hline PI VL - endothelin I & 0.732 & $<0.05$ \\
\hline C-reactive protein - $\mathrm{CO}$ & -0.383 & $>0.05$ \\
\hline C-reactive protein - endotelin I & 0.808 & $<0.05$ \\
\hline
\end{tabular}

\section{Table 11}

Correlation between indicators of central hemodynamics and NO metabolites in the Group I

\begin{tabular}{lcc}
\hline Indices & $\mathrm{R}$ & $\mathrm{P}$ \\
\hline MAP-NO & 0.443 & $>0.05$ \\
EDLVD-NO & 0.060 & $>0.05$ \\
ESLVD-NO & 0.059 & $>0.05$ \\
SV-NO & 0.084 & $>0.05$ \\
CO-NO & 0.071 & $>0.05$ \\
EF-NO & 0.132 & $>0.05$ \\
SVRI-NO & 0.500 & $>0.05$ \\
\hline
\end{tabular}

Thus, our obtained data on the state of central hemodynamics of children with meningococcal septic shock in general are similar to the work of Have et al. (2000) - the only ultrasound research conducted on hemodynamics in meningococcus infected children, which also showed a significant reduction in left ventricular systolic function and its prognostic significance in poor output. However, our findings may create a discussion on important role of hypovolemia in the development of septic shock in children. Identifying the truth on this matter is extremely important, because the current existing recommendations on the management of septic shock (including meningococcal shock in children) give preference to aggressive infusion therapy as the first step in treatment (Brierley et al., 2009; Nadel, 2016). However, the results of our studies show the negative effects of aggressive infusion in patients with systolic heart failure! At the same time, we observe another approach to using infusion therapy in adults with septic shock, which includes minimization of the liquid volumes (Malbrain et al., 2014; Malbrain et al., 2015; Chen and Kollef, 2015). In a recent published study, the benefits of restrictive fluid therapy in comparison with standard infusion at septic shock in adults were presented (Hjortrup et al., 2015). The study RENAL showed that negative daily water balance was associated with clinical improvement in these patients (Bellomo et al., 2012).

The researched changes in the regional blood flow distribution in the splanchnic areas in patients with meningococcal septic shock indicate that the organs in splanchnic areas are not exposed to ischemia. On the contrary, in terms of early septic shock we found hyper perfusion on the basin of the upper mesenteric artery and increase (mainly due to portal) of total hepatic blood flow, which may well reflect increased oxygen need in the liver and intestine. The latter could be reached through the activation of immune cells (associated with intestine lymphoid tissue and liver Kuepfer macrophages) and their participation in the systemic inflammatory response. Also hemodynamic lesion of these organs may rather be due to the hyper perfusion than ischemia. The same applies to the kidneys. The role of direct prerenal ischemia in the development of acute kidney damage in sepsis is becoming more doubtful. Kidney damage and venous hypertension indicate intraorganic microcirculatory disorders, which were proven in the form of the pulse growth index of the main renal veins found in our study (Zarbok et al., 2014).

The role of NO molecules in meningococcal septic shock should be revised. The image of "sinister monster" responsible for cardiac dysfunction and uncontrolled arterial hypotension in septic shock should be rejected, because NO played a leading role in maintaining microcirculation and perfusion in vital parts of the vascular system (Duran-Bedolla et al., 2014). This is proved by the leading foreign publications, as well as the results of correlation analysis in our study. Unlike the current Guidelines SSC (2016), the data we obtained can be a theoretical basis for the application of NO donor in complex intensive therapy of hemodynamic disorders associated with meningococcal septic shock with the aim of improving the outcomes.

\section{Conclusions}

Meningococcal septic shock in children is characterized by significant impairment of the central hemodynamics, which consists in lowering blood pressure, tachycardia, and suppression of left ventricular systolic function. The data we have obtained on the nature of hemodynamic disorders in children suffering from meningococcal septic shock should be used to substantiate a more cautious approach to infusion therapy and earlier use of drugs with positive inotropic effects.

Given the significant increase of NO production, which correlates with splanchnic circulation indicators, we can assume that hyperproduction of NO and hyperperfusion in the splanchnic zones play a protective role against the development of organ failure, because they are associated with a lower score on the PRISM scale.

The increased resistance index in the main renal veins in patients with meningococcal septic shock is closely correlated with the creatinine level, so it can be used as a non-invasive sign of acute kidney injury. In contrast to the recommendations of the Surviving Sepsis Campaign (2016) concerning the undesirable use of arginine to increase the level of NO in adults with septic shock, the use of arginine and other donors of NO in children with meningococcal septic shock should be the subject of further research.

\section{References}

Bellomo, R., Cass, A., Cole, L., Finfer, S., Gallagher, M., Lee, J., Lo, S., McArthur, C., McGuiness, S., Norton, R., Myburgh, J., Scheinkestel, C., \& $\mathrm{Su}, \mathrm{S} .(2012)$. An observational study fluid balance and patient outcomes 
in the randomized evaluation of normal vs. augmented level of replacement therapy trial. Critical Care Medicine, 40(6), 1753-1760.

Bernal, W. (2016). The liver in systemic disease: Sepsis and critical illness. Clinical Liver Disease, 7(4), 88-91.

Boisrame-Helms, J., Kremer, H., Schini-Kerth, V., \& Meziani, F. (2013). Endothelial dysfunction in sepsis. Current Vascular Pharmacology, 11(2), 150-160.

Carcillo, J. A., \& Fields, A. I. (2002). Clinical practice parameters for hemodynamic support of pediatric and neonatal patients in septic shock. Critical Care Medicine, 30(6), 1365-1378.

DiLorenzo, A. N., \& Schell, R. M. (2014). Morgan Mikhail's clinical anesthesiology, 5th Edition. Anesthesia and Analgesia, 119(2), 495-496.

Chen, C., \& Kollef, M. H. (2015). Targeted fluid minimization following initial resuscitation in septic shock. Chest, 148(6), 1462-1469.

Corrêa, T. D., Filho, R. R., Assunção, M. S. C., Silva, E., \& Lima, A. (2017). Vasodilators in septic shock resuscitation. Shock, 47(3), 269-275.

De Backer, D., Orbegozo Cortes, D., Donadello, K., \& Vincent, J. L. (2013). Pathophysiology of microcirculatory dysfunction and the pathogenesis of septic shock. Virulence, 5(1), 73-79.

De Backer, D., Donadello, K., Sakr, Y., Ospina-Tascon, G., Salgado, D., Scolletta, S., \& Vincent, J. L. (2013). Microcirculatory alterations in patients with severe sepsis. Critical Care Medicine, 41(3), 791-799.

Dellinger, R. P., Levy, M. M., Rhodes, A., Annane, D., Gerlach, H., Opal, S. M., Sevransky, J. E., Sprung, C. L., Douglas, I. S., Jaeschke, R., Osborn, T. M., Nunnally, M. E., Townsend, S. R., Reinhart, K., Kleinpell, R. M., Angus, D. C., Deutschman, C. S., Machado, F. R., Rubenfeld, G. D., Webb, S. A., Beale, R. J., Vincent, J. L., \& Moreno, R. (2013). Surviving sepsis campaign. Critical Care Medicine, 41(2), 580-637.

Duran-Bedolla, J., de Oca-Sandoval, M. A. M., Saldana-Navor, V., Villalobos-Silva, J. A., Rodriguez, M. C., \& Rivas-Arancibia, S. (2014). Sepsis, mitochondrial failure and multiple organ dysfunction. Clinical and Investigative Medicine, 37(2), 58-69.

Gomez, H., Ince, C., De Backer, D., Pickkers, P., Payen, D., Hotchkiss, J., \& Kellum, J. A. (2014). A unified theory of sepsis-induced acute kidney injury. Shock, 41(1), 3-11.

Hamborsky, J., \& Kroger, A. (Eds.). (2015). Epidemiology and prevention of vaccine-preventable diseases. Public Health Foundation, 512.

Hagmolen of ten Have, W., Wiegman, A., van den Hoek, G. J., Vreede, W. B., \& Derkx, H. H. F. (2000). Life-threatening heart failure in meningococcal septic shock in children: Non-invasive measurement of cardiac parameters is of important prognostic value. European Journal of Pediatrics, 159(4), 277-282.

Hjortrup, P. B., Haase, N., Bundgaard, H., Thomsen, S. L., \& Winding, R. (2016). Restricting volumes of resuscitation fluid in adults with septic shock after initial management: The CLASSIC randomised, parallel-group, multicentre feasibility trial. Intensive Care Medicine, 42(11), 1695-1705.

Ince, C., Mayeux, P. R., Nguyen, T., Gomez, H., Kellum, J. A., OspinaTascón, G. A., \& De Backer, D. (2016). The endothelium in sepsis. Shock, 45(3), 259-270.
Lupp, C., Baasner, S., Ince, C., Nocken, F., Stover, J. F., \& Westphal, M. (2013). Differentiated control of deranged nitric oxide metabolism: A therapeutic option in sepsis? Critical Care, 17(3), 311.

Malbrain, M. L. N. G., Marik, P. E., Witters, I., Cordemans, C., Kirkpatrick, A. W., Roberts, D. J., \& Van Regenmortel, N. (2014). Fluid overload, deresuscitation, and outcomes in critically ill or injured patients: A systematic review with suggestions for clinical practice. Anestezjologia Intensywna Terapia, 46(5), 361-380.

Malbrain, M. L. N. G., Van Regenmortel, N., \& Owczuk, R. (2015). It is time to consider the four D's of fluid management. Anestezjologia Intensywna Terapia, 47, 1-5.

Nadel, S. (2016). Treatment of meningococcal disease. Journal of Adolescent Health, 59(2), S21-S28.

Prin, M. (2015). Hepatosplanchnic circulation in cirrhosis and sepsis. World Journal of Gastroenterology, 21(9), 2582.

Rhodes, A., Evans, L. E., Alhazzani, W., Levy, M. M., Antonelli, M., Ferrer, R., Kumar, A., Sevransky, J. E., Sprung, C. L., Nunnally, M. E., Rochwerg, B., Rubenfeld, G. D., Angus, D. C., Annane, D., Beale, R. J., Bellinghan, G. J., Bernard, G. R., Chiche, J. D., Coopersmith, C., De Backer, D. P., French, C. J., Fujishima, S., Gerlach, H., Hidalgo, J. L., Hollenberg, S. M., Jones, A. E., Karnad, D. R., Kleinpell, R. M., Koh, Y., Lisboa, T. C., Machado, F. R., Marini, J. J., Marshall, J. C., Mazuski, J. E., McIntyre, L. A., McLean, A. S., Mehta, S., Moreno, R. P., Myburgh, J., Navalesi, P., Nishida, O., Osborn, T. M., Perner, A., Plunkett, C. M., Ranieri, M., Schorr, C. A., Seckel, M. A., Seymour, C. W., Shieh, L., Shukri, K. A., Simpson, S. Q., Singer, M., Thompson, B. T., Townsend, S. R., Van der Poll, T., Vincent, J. L., Wiersinga, W. J., Zimmerman, J. L., Dellinger, R. P. (2017). Surviving sepsis campaign: International guidelines for management of sepsis and septic shock: 2016. Intensive Care Medicine, 74.

Sadarangani, M., Scheifele, D. W., Halperin, S. A., Vaudry, W., Le Saux, N., Tsang, R. (2015). Outcomes of invasive meningococcal disease in adults and children in Canada between 2002 and 2011: A prospective cohort study. Clinical Infectious Diseases, 60(8), e27-e35.

Schnell, D., Deruddre, S., Harrois, A., Pottecher, J., Cosson, C., Adoui, N., Benhamou, D., Vicaut, E., Azoulay, E., Duranteau, J. (2012). Renal resistive index better predicts the occurrence of acute kidney injury than cystatin C. Shock, 38(6), 592-597.

Viner, R. M., Booy, R., Johnson, H., Edmunds, W. J., Hudson, L., Bedford, H., Kaczmarski, E., Rajput, K., Ramsay, M., Christie, D. (2012). Outcomes of invasive meningococcal serogroup B disease in children and adolescents (MOSAIC): A case-control study. The Lancet Neurology, 11(9), 774-783.

Zhao, Y., Vanhoutte, P. M., \& Leung, S. W. S. (2015). Vascular nitric oxide: Beyond eNOS. Journal of Pharmacological Sciences, 129(2), 83-94.

Zarbock, A., Gomez, H., \& Kellum, J. A. (2014). Sepsis-induced acute kidney injury revisited. Current Opinion in Critical Care, 20(6), 588-595. 